\title{
"Dichosa mujer de piedra": a inauguración da estatua de Emilia Pardo Bazán na Coruña (1916)
}

\author{
Manuel González Prieto \\ (CASA-MUSEO EMILIA PARDO BAZÁN) \\ uman185@hotmail.com
}

(recibido novembro/2017, revisado xaneiro/2018)

RESUMEN: Nesta achega abórdanse dous fitos importantes na vida de Emilia Pardo Bazán e que aconteceron no ano 1916: o 12 de maio, o rei Afonso XIII asinaba a Real Orde que nomeaba a Pardo Bazán "catedrático numerario de Literatura contemporánea de las Lenguas neo-latinas de la Universidad Central", e o 15 de outubro inaugurábase a escultura en homenaxe a Emilia Pardo Bazán na Coruña, iniciativa que partiu, no ano 1905, dun grupo de coruñeses residentes en Lugo. Nos anexos reprodúcense o discurso lido por Emilia Pardo Bazán na recepción no Concello da Coruña, o 17 de outubro de 1916, e un artigo da mesma, publicado o 8 de novembro de 1916, no xornal El Liberal, e no que mostraba as súas impresións sobre a inauguración da estatua.

PALABRAS CLAVE: Emilia Pardo Bazán, catedrática, homenaxe, escultura, Manuel Casás, inauguración.

ABSTRACT: This approach will address two important events in the life of Emilia Pardo Bazán that occurred in 1916: on May 12, King Alfonso XIII signed the Royal Order that named Pardo Bazán "professor of Contemporary Literature of Neo Languages -Latinas of the Central University ", and on October 15 the sculpture was inaugurated in homage to Emilia Pardo Bazán in La Coruña, an initiative that started, in 1905, of a group of residents from Coruña in Lugo. In the annexes the speech read by Emilia Pardo Bazán at the reception of the City Council of La Coruña, on October 17, 1916, and an article published on November 8, 1916, in the newspaper El Liberal, and in the that showed his impressions about the inauguration of the statue.

KEY WORDS: Emilia Pardo Bazán, professor, sculpture, Manuel Casás, homage.

Dichosa mujer de piedra, a la cual el tiempo no injuria, resbalando impotentes los años por su lisa frente, sin imprimir en ella una arruga, sin doblar su erguida espalda, sin apagar sus ojos, faltos de pupila y abiertos ampliamente a la claridad de soles y lunas, al parpadeante esplendor de las estrelladas noches. ¡Dichosa mujer, siempre bañada en aire libre, siempre impregnada de brisa salitrosa del Cantábrico, en el puerto marinedino!

(Emilia Pardo Bazán ${ }^{1}$ )

\footnotetext{
${ }^{1}$ El Liberal (Madrid, 8-XI-1916, p. 1) e La Voz de Galicia (A Coruña, 10-XI-1916, p. 1).
} 
O ano 1916 é fundamental na traxectoria académica da condesa de Pardo Bazán. Dna. Emilia conta coa bagaxe dunha dilatada carreira literaria e xornalística, que é recoñecida polos seus contemporáneos. A cátedra que se lle outorga constitúe un feito excepcional de grande importancia histórica no ámbito académico: por primeira vez unha muller é nomeada "catedrática en Lenguas Neolatinas" na Universidade Central. Isto leva a que algúns a traten de equiparar a Rosalía e a Concepción Arenal, e que polo tanto é merecente de ser homenaxeada e mostrada como un símbolo igual ca elas. Con este fin ponse en marcha unha homenaxe, xestada en Lugo, pero que se materializaría na súa cidade natal da Coruña. A homenaxe consistiu no levantamento dunha estatua e a organización dun acto no que tomaron parte todas as forzas vivas da cidade e de Galicia. Aínda que dona Emilia non asistiu persoalmente a toda a celebración, non hai dúbida de que esta encheu o ego da condesa, que se mostra especialmente agradecida á súa cidade.

Un século despois, o legado de modernidade de dona Emilia segue vivo e, en moitos aspectos, de actualidade, sen pasar o tempo por el, como pola "dichosa mujer de piedra", trasunta da condesa. As súas palabras foron premonitorias: a súa modernidade permanece vixente como a escultura inaugurada hai máis de cen anos, a muller de pedra pola que non pasa o tempo, sempre bañada en aire libre impregnado da humidade e da brétema marinedina.

Neste traballo só pretendemos facer unha achega documental con novas arredor da cátedra e recepción da nova na Coruña, e a inauguración da estatua e a súa celebración, con todos os rituais que acostuman acompañar estes actos.

\section{EMILIA PARDO BAZÁN, CATEDRÁTICA}

O 12 de maio de 1916, o rei Afonso XIII asina a Real Orde que nomea a Pardo Bazán "catedrático numerario de Literatura contemporánea de las Lenguas neo-latinas de la Universidad Central". Atopamos as primeiras noticias en Gaceta de Madrid ${ }^{2}$, e poucos días despois, tamén na prensa local da Coruña ${ }^{3}$.

A nova circulou rapidamente e os parabéns non se fixeron esperar. Entre outras institucións, a Comisión permanente da Deputación Provincial da Coruña ${ }^{4}$ enviou dous telegramas, un á condesa mostrándolle a súa satisfacción e o merecido do nomeamento, e outro ao ministro de Instrución pública no que lle notifica a satisfacción da Deputación polo acto de xustiza que supoñía o nomeamento da condesa. A Asociación de Prensa da Coruña, a través de José María Ozores ${ }^{5}$, o seu presidente, tamén lle fai patente a súa alegría

\footnotetext{
2 Gaceta de Madrid, n. 135 (14-V-1916), p. 295. Pódese consultar un documentado traballo sobre este nomeamento no número 4, do ano 2006, da revista La Tribuna, debido á profesora Ángeles Quesada Novás.

3 La Voz de Galicia xa o 15 de maio publica un telegrama dando conta do nomeamento, e amplía a nova o día seguinte, mentres que El Noroeste, o 16 e na súa primeira plana, reproduce o texto da Real Orde.

${ }^{4}$ La Voz de Galicia (20-V-1916), p. 1 e El Noroeste (20-V-1916), p. 1.

5 La Voz de Galicia (20-V-1916), p. 1 e El Noroeste (20-V-1916), p. 1.
} 
aos mesmos destinatarios. A resposta do ministro pouco se fixo esperar ${ }^{6}$. E polos mesmos días responde tamén Dona Emilia, ofrecendo esta honra á súa cidade natal.

Si alguna honra recojo con la iniciativa del Gobierno, me complazco en ofrecerla a mi ciudad natal, con la expresión de constante recuerdo. Condesa Pardo Bazán ${ }^{7}$.

O Concello da Coruña tamén mostrou a súa alegría, e o 7 de xullo unha comisión, presidida polo alcalde Manuel Casás, visitou o Pazo de Meirás, lugar onde residía no verán a familia Pardo Bazán, e entregoulle en man á condesa unha mensaxe de felicitación que asinou o propio alcalde. No fondo documental da escritora custodiado no arquivo da Real Academia Galega consérvase esta carta e unha fotografía dos asistentes á visita, que pertencen ao fondo de Manuel Casás, e que reproducimos a continuación ${ }^{8}$.

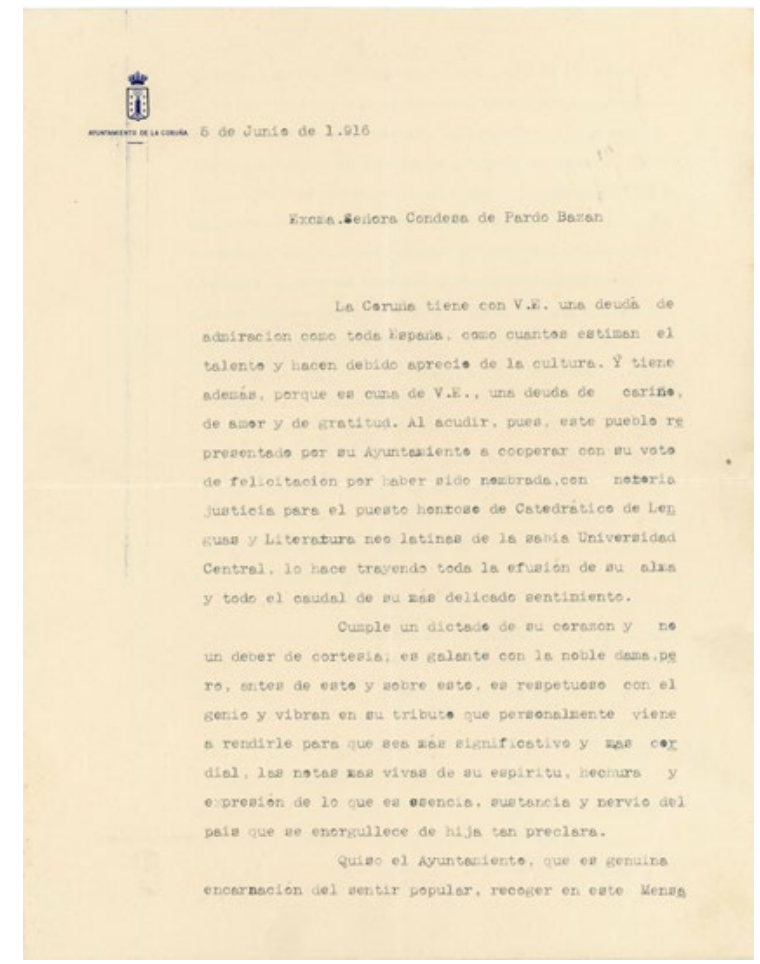

\footnotetext{
$\overline{6}$ La Voz de Galicia (22-V-1916), p. 1 e El Noroeste (22-V-1916), p. 1.

${ }^{7}$ La Voz de Galicia (22, 24-V-1916), p. 1 e El Noroeste (22, 24-V-1916), p. 1.

8 Pódese ler unha crónica da visita, en La Voz de Galicia (8-VII-1916), p. 1.
} 
Je, pobre de catilo, pero rice en ventiafento,ise foll ofuciones que fueron llegando o V. B. deade que ee is

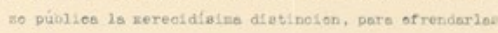
tedes en une que eo elnteese y ouse, rothejo y wanifeate olon elocuente y solisarda de lo opinión coruliess.

Cuando eate Kenea e lle sue a zanos de

Y. K. aletido portador de él uns Cosielon del Conoejo ae contarion por centerarea 200 teativoniou de felicita olon rectaldoe de codea partea de Euperio y del extren jere, donde zas ocrea de 15 lluetre Condeas de Paxdo Basion, tieren un explio cando y un horizonte vastiefso.

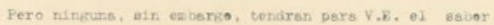
de éste, pues vo eaturado de efluvios de a or y repre venta 28 sietre nedre.

Honrs ea pera Us 21018 Que ses V.K. es jeto de eatos hopenajea, porque con exlo recibe preas

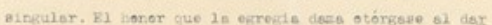
le pueato en la Univerasdad Central nloenma o Goliofo

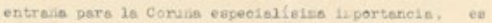
tisiore de ar walo pers is sujer gajlezs y conatituye le gitine golerdán pero do intelectuedsded texenins de 10

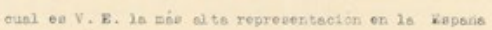
contexporínee.

Vueatro pliso que ea cincel de prove coetra y orizente, vieatro ourtura que oo he conquils tedo pueato prees ne nte en led Letros, deterninaron ea te solesne y pibjlco reconocistonto ol seber, ol talen

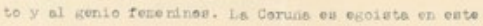

orpecta y quiere pors 81 blgo de tonto honor. Viene a of cecer o bu hije liuatre el aentibients de corino, de devoción $y$ de psrablén entralasta, $y, s 1$ encontrarae onte el10, pors ousplir un scuexio edoptedo por el Avm

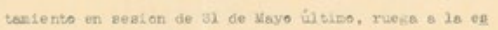

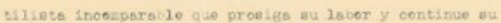
obre literarie, que ee coet el fuligor que peralte ver

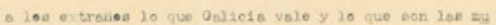
jeres de eate tierre.

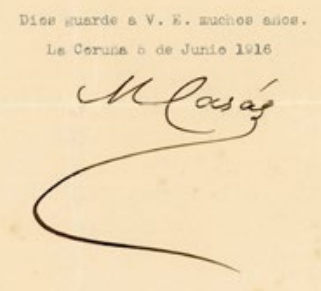




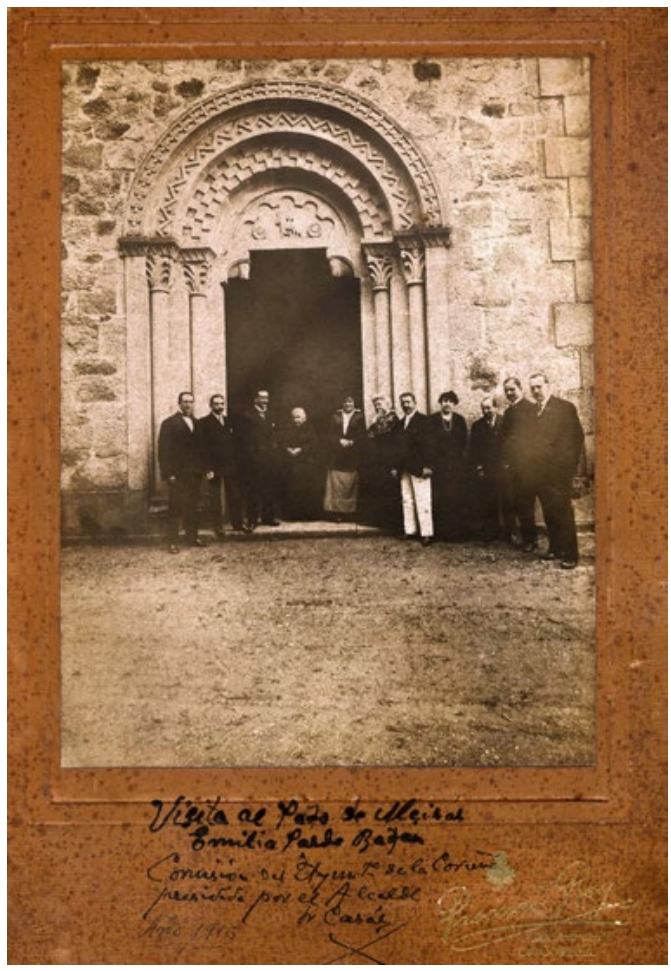

Na fotografía, de esquerda a dereita, Martín Martínez, Barreiro Noya, Manuel Casás, Amalia de la Rúa, Carmen Quiroga, Emilia Pardo Bazán, José Cavalcanti, Blanca Quiroga, home sen identificar, Gerardo Abad Conde e personaxe sen identificar.

Mais non todo foron felicitacións, pois a concesión da cátedra non naceu sen polémica, críticas e oposición, xa que unha parte do Claustro da Universidade Central negouse a aceptar tal nomeamento, tal e como recolle o xornal La Voz de Galicia ao dar a noticia da publicación da Real Orde. O artigo tamén pon énfase na valía da coruñesa e na reivindicación que hai detrás do nomeamento ${ }^{9}$ dunha muller catedrática. Cómpre lembrar que os ataques á dotación da nova cátedra xurdiron meses atrás, cando a prensa fai eco dos primeiros rumores que sinalan a Pardo Bazán como a súa beneficiaria. Estes ataques tamén chegaron á súa cidade natal e envoltos en críticas máis ou menos veladas. Mostra disto é a columna que asinou Julio Camba no mes de marzo en La Voz de Galicia e que titulou "Doña Emilia, romanonista"10, na que ironiza coa autodenominación de "romanonista" que Ile dera á novelista Domingo Tejera, nunha entrevista feita para o xornal madrileño La Acción ${ }^{11}$. Para Camba, é natural que Pardo Bazán se considere como tal, tendo en conta que foi Romanones quen a nomeou conselleira de Instrución Pública en 1910, e que a cátedra foi impulsada por un goberno que el mesmo preside.

\footnotetext{
9 La Voz de Galicia (20-V-1916), p. 1.

10 La Voz de Galicia, (3-III-1916), p. 1.

${ }^{11}$ La Acción, Madrid (28-II-1916), p. 3.
} 


\section{BREVE HISTORIA DUNHA HOMENAXE}

En 1905 algúns colegas de Pardo Bazán recoñeceron publicamente os méritos da escritora $^{12}$, e o xornal La Época, preguntábase:

¿Qué recompensas ha obtenido, hasta el momento presente, la insigne escritora? ${ }^{13}$

É curioso que a comezos deste ano ${ }^{14}$, e coma se respondesen á pregunta do xornal ou pregunta semellante, un grupo de coruñeses residentes en Lugo -Alfredo Souto, Cándido López Rúa, Indalecio Várela Lenzano, Adolfo Marino Yáñez, Donato Naveira, Emilio Tapia e Manuel Amor Meilán- teñen a idea de erixir un monumento para lle render homenaxe a Pardo Bazán na súa cidade natal, e así llo fan saber nunha carta pública asinada o 7 de xaneiro de $1905^{15}$. Catro días despois, ela contestou desde Madrid, aceptando a proposta gustosamente.

Acepto, pues, no engreída, sino al contrario, necesitada de apoyarme en la simpatía que con tal espontaneidad viene a mí, y acepto en vida, porque en vida he sufrido. Acepto, porque el mármol y el bronce que me ofrecéis, paisanos y amigos míos, escritores, artistas, intelectuales de la tierra gallega, en vez de serme duro y frío, emitirá calor para mi corazón en los años postreros de mi jornada. Y vuestro mensaje, al que respondo, lo archivarán mis hijos como timbre de gloria y corona de mi carrera. ${ }^{16}$

E admiradores e admiradoras da coruñesa participaron na iniciativa, na que se contemplou conseguir os fondos necesarios para poñela en marcha, por medio dunha subscrición popular.

Por lo mismo, el citado proyecto se realizará por subscrición, y a ella habrán de contribuir los amantes de las bellas letras, los particulares, que sienten admiración por su genial paisana, y las corporaciones oficiales y centros, que no pueden mostrarse agenos a la cooperación del aludido pensamiento. ${ }^{17}$

\footnotetext{
12 Como podemos ler no xornal La Época, o 16 de xaneiro de 1905: «Desde Santa Teresa acá-dice D. Juan Valera-, ninguna escritora española iguala a esta ni en saber, ni en discreción, ni en ingenio».

13 La Época, Madrid (16-I-1905).

14 Na tese La oratoria de Emilia Pardo Bazán (Discursos, Conferencias, Lecturas Públicas) de Ma Aránzazu Guzmán Guzmán, a autora sinala que a xénese da escultura en homenaxe a dona Emilia foi a raíz da súa participación como mantedora nas Festas de San Froilán de Lugo en 1906, mais como lemos na prensa, en realidade a iniciativa partiu no ano 1905, dun grupo de coruñeses residentes en Lugo. Un ano despois, con motivo das Festas de San Froilán, celebradas entre os días 4 e 10 de outubro, unha excursión coruñesa visitou Lugo por iniciativa da Reunión Recreativa e Instrutiva de Artesáns da Coruña. A comisión lucense organizadora do acto, encabezada por Amor Meilán, director de El Regional, decidiu que Pardo Bazán fose a mantedora do acto (El Regional, Lugo, 8-X-1906. Nas páxinas do xornal atopamos o discurso completo lido pola coruñesa no Certame de Composición Musical).

15 La Época, (25-I-1905).

16 La Época, (27-I-1905).

${ }^{17}$ El Correo Gallego, Ferrol (9-I-1905).
} 
Mais haberá que agardar a comezos de xuño de 1916, para que esta iniciativa chegue a bo porto ${ }^{18}$. E no artigo "El monumento a la condesa de Pardo Bazán. Sólo falta colocarlo", Amor Meilán e Alejandro Barreiro, membros da comisión promotora lucense, informaron ao público de que a escultura estaba xa rematada e do seu emprazamento nos xardíns de Méndez Núñez.

Lo estaba ya hace tres meses; pero, a mayor abundamiento, encuéntrome hoy mismo con una carta del escultor en la que me dice, sin quitar ni poner punto ni coma: "El monumento está dispuesto para enviarlo cuando ustedes me lo indiquen".

[...] En el pasado mes de Julio, cuando Coullaut Valera -el escultor- y yo estuvimos en esa ciudad, eligió aquél, como uno de los parajes de su especial predilección, el parterre de entrada a los jardines, a espaldas de la estatua de Carballo, al fin de un árbol -creo que es un magnolio- y enfrontando con los Cantones. Recuerdo que la designación fue hecha ante el entonces alcalde Sr. Ozores, la comisión municipal de Paseos y el arquitecto Sr. Mariño; éstos por lo menos ${ }^{19}$.

Mais a Comisión de Paseos e Festas acordou, nunha reunión do sábado 8 de xullo, ás 17.30 horas, e coa presenza de Juan González Rodríguez, o seu presidente, que a estatua fose colocada na praza de Ourense, "rodeando al monumento de adecuados jardines" ${ }^{20}$.

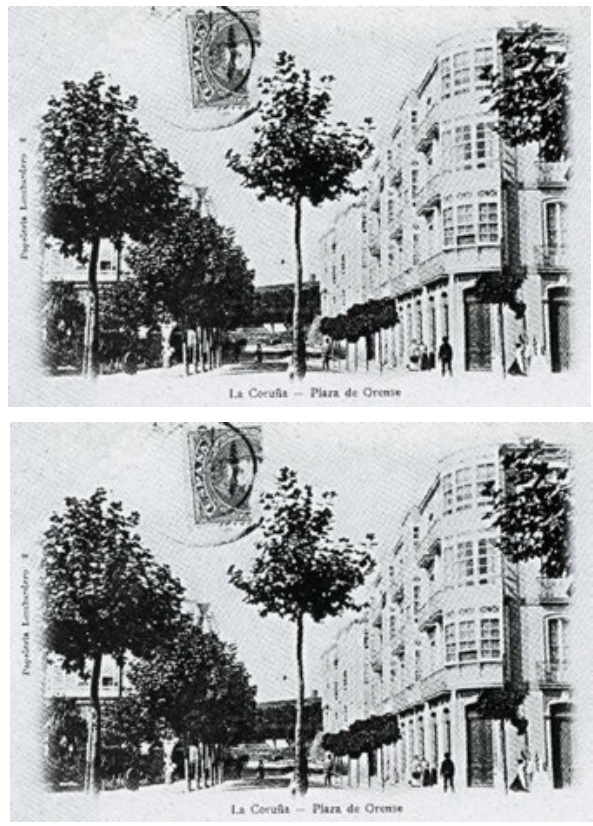

Tarxetas postais con vistas da praza de Ourense nos anos 1900-1930 (Tomadas do Catálogo de la colección de postales: Arquivo Municipal, A Coruña, Concello da Coruña, 1998, p. 122).

\footnotetext{
18 O 15 de outubro de 1916, no acto inaugural, Amor Meilán explicou nun sentido discurso a xénese do monumento, e dixo tamén que outros e debidos laudos pospuxeron tal recoñecemento.

19 La Voz de Galicia, (4-VI-1916).

${ }^{20}$ La Voz de Galicia (9-VII-1916), p. 1, e El Noroeste (9-VII-1916), p. 1.
} 
A decisión da Comisión, contraria aos desexos do escultor e promotores lucenses, provocou unha airada resposta de Amor Meilán en forma de carta aberta, publicada en El Noroeste, o 20 de xullo. Na carta, Meilán quéixase de que o seu emprazamento sexa na Praza de Ourense e denuncia a actitude displicente do Concello coruñés co proxecto, que levaba dous anos de retraso, por culpa do consistorio herculino. Deste xeito, o Concello reconsiderou a súa postura, e o 9 de agosto aprobou situar a estatua nos Xardíns de Méndez Núñez, e no lugar pensado polo escultor Coullaut Valera ${ }^{21}$. O 12 de agosto, poucos días despois, atopamos a confirmación da súa localización, na carta aberta asinada por Amor Meilán, o secretario da comisión promotora luguesa, e na que informa de que o lugar escollido para colocar a estatua será efectivamente a entrada dos Xardíns de Méndez Núñez e de que a súa inauguración terá lugar o 8 de setembro. Nesa carta solicitoulle tamén ao alcalde as debidas obras de cimentación, "antes de que el escultor envíe la estatua" ${ }^{\prime 22}$.

Casás deu orde de inmediato ao señor Mariño, o arquitecto municipal, de facilitar as obras coa rapidez requirida pola comisión lucense, e o 19 de agosto xa atopamos novas que ratifican a localización da estatua e que informan sobre o acto, que será sinxelo, por indicación de Pardo Bazán. Será Carmen, a filla da homenaxeada, quen descubrirá a escultura, que estará cuberta cunha bandeira nacional e rodeada por unha instalación de flores "en la pradera que existe frente a la entrada principal del jardín, hacia la izquierda, situado en la misma línea que determina la escultura de Concepción Arenal"23.

O 15 de outubro de 1916, data na que se celebrou o acto de homenaxe a Pardo Bazán, caeu en domingo. Nas páxinas do xornal La Voz de Galicia atopamos esta carta da homenaxeada, que recibe o día anterior Abad Conde, alcalde accidental e presidente da comisión xestora da homenaxe, na que Pardo Bazán explica as razóns polas que non estará presente no solemne acto inaugural e na que anuncia a asistencia dos seus fillos. Nas páxinas do xornal agrade o recoñecemento a Lugo, á súa cidade natal, e ao xornal La Voz de Galicia:

Amigo y conciudadano: Tengo el honor de recibir su carta, con la noticia oficial de que va a ser inaugurado el día 15 del corriente el monumento que, por iniciativa de la ciudad de Lugo y franca y cariñosa acogida de la de la Coruña, se alza en céntrico y señalado lugar del pueblo donde he nacido.

Alta sería siempre la recompensa para mi labor, si el monumento se erigiese terminada mi carrera mortal, y es extraordinaria al poder contemplarla mis ojos y que su alegría dilate mi corazón.

Tal premio, sin embargo, deseo recibirlo siéndome permitido no estar presente al solemne acto inaugural, pues sin alardear de modestia, la guardo dentro de mi espíritu, y me produciría un sentimiento de confusión profunda asistir al homenaje tan singular, que mis paisanos y contemporáneos consagran a una existencia dedicada a las letras y al arte.

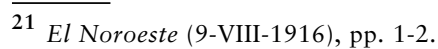

22 La Voz de Galicia (12-VIII-1916).

23 La Voz de Galicia (19-VIII-1916).
} 
Presentes a la ceremonia estarán mis hijos, en quienes es lícita la creencia de que merezco tanta honra reunida; y al enviarles, envío lo mejor de mí misma, con la ofrenda absoluta de mi gratitud.

Por fortuna mía, no se concreta mi gratitud a la prensa, sino que, dulce obligación, he de repartirla entre elementos diversos. En una ciudad gallega donde apenas he residido dos o tres días, surgió la idea de tributar nunca visto testimonio de estimación a mi obra. Donde creí tener sino algún amigo, hallé esa devoción intensa y ferviente que realiza las empresas más arduas. Faltaba que mi ciudad natal recibiese con amor de madre la fraternal ofrenda y lo hace, pródigamente, como lo dice su generosidad probada. Y así me da el destino lo que pude soñar en la juventud, al revelarse la vocación, cuando fantaseamos lo que traerá en sus oscuros limbos, lo venidero. Nada me debe mi tierra, pero si algo me debiese, bien me paga.

Reciba usted, con estos renglones, y una vez más, la parte que en este reconocimiento mío le corresponde al director y a la hoja, y créame siempre su siempre afectísima ${ }^{24}$.

\section{UN ENFRONTAMENTO SOTERRADO}

Hai varias cuestións que chaman a atención: a decisión da escritora de non acudir á inauguración da escultura, mais si acudir ao banquete organizado despois; a ausencia de Manuel Casás, o alcalde da Coruña, no acto; as desavinzas entre o Concello da Coruña e a comisión de Lugo promotora da escultura de Coullaut; e a tardanza do Concello á hora de felicitar a autora pola obtención da cátedra, xa que, como dixemos, os parabéns oficiais do consistorio herculino non lle foron entregados á escritora até o 7 de xullo, e non por iniciativa de Casás, o alcalde, senón por iniciativa do concelleiro Santiago Casares Quiroga $^{25}$.

Naquel tempo había un enfrontamento persoal entre Casás e Pardo Bazán, e, anos despois e lembrando a figura da novelista, Casás recoñece esas diferenzas. Cómpre lembrar tamén que Pardo Bazán non asistiu á festa dedicada a Rosalía, malia ser convidada. A homenaxe, por iniciativa de Casás, celebrouse no Teatro Rosalía, na Coruña, na noite do primeiro de setembro, nela participaron poetas da altura de Pondal, Rey Soto, Cabanillas, Lisardo Barreiro, Filomena Dato, Francisca Herrera e Noriega Varela, e léronse unhas

\footnotetext{
$\overline{24}$ La Voz de Galicia (15-X-1916).

25

25 Casares fixo a proposta no pleno do Concello que se celebrou o 31 de maio de 1916. Casás, o alcalde, respondeu dunha forma un tanto airada, xa que interpretou a proposta coma un ataque persoal (La Voz de Galicia, 1-VI-1916, p. 2 e El Noroeste, 1-VI-1916, p. 1). A idea era que unha comisión coruñesa, que nos días seguintes ía a Madrid, para entrevistarse con autoridades do goberno, entregase a felicitación en man á autora coruñesa, mais a comisión cruzouse polo camiño con Pardo Bazán, que acompañada pola súa familia estaba trasladándose a Meirás para pasar o verán. É por iso que a entrega da misiva tivo que adiarse, ata que finalmente, no mes xullo e en Meirás, puido producirse o acto de entrega da mesma (La Voz de Galicia, 8-VII-1916, p. 1).
} 
cuartillas de Manuel Murguía. O mantedor foi Vázquez de Mella. Dona Emilia non acudiu, malia estar "a poca distancia, en su residencia del Pazo de Meirás" ${ }^{26}$, e Casás engadiu:

Es bien sabido que doña Emilia dedicó entusiastas elogios a Rosalía de Castro, y es suficiente recordar lo que de ella dice en su interesante De mi tierra. Pero, aparte de esto, se engendró entre los escritores galáicos un general descontento por insinuaciones mortificantes que se le atribuyeron últimamente a la autora de El Cisne de Vilamorta, contra nuestra admirada Rosalía, que consideraron injusto reproche a la característica sentimental de la incomparable intérprete del lirismo de nuestra tierra. Y aun sonó la palabra "chorimiqueira" como supremo ultraje. También se citaron ciertas frases molestas para el marido de nuestra poetisa, el insigne Murguía.

$[\ldots]$

Lo lamentable es que duró por largo tiempo esta situación para unos y para otros, y aun nosotros no hemos podido sustraernos a tal ambiente con ocasión de cierto episodio que ha tenido excesiva notoriedad, hasta el punto de que en una de las visitas que hicimos como Alcalde de La Coruña al Palacio Real -donde doña Emilia gozaba de escasas simpatías, sin duda por su filiación notoriamente tradicionalista- nos hemos visto sorprendidos por una pregunta de don Alfonso XIII:

-Diga usted. ¿Qué le ocurrió con la Pardo Bazán?

Todo esto, repetimos, petenece a la menuda anécdota, y con la muerte de la ilustre novelista española que tantas páginas de admirable literatura ha publicado, aquellos resquemores han desaparecido, y es de justicia proclamar que ella honró a Galicia con un nombre pleno de los resplandores de la fama. ${ }^{27}$

Aínda que Casás quixo situar os desacordos coa autora no marco das difíciles relacións que ela tivo con destacados membros do galeguismo, das súas palabras emerxe un certo grao de encontro ou simpatía persoal coa autora, xa que cómpre ter en conta que a relación entre ambos comezou con bo pé, aló polo ano 1890, cando Casás consegue que Pardo Bazán Ile facilite unha carta prólogo para a súa obra Agape y la revolución priscilianista en el siglo IV (A Coruña, 1895) ${ }^{28}$. O avogado coruñés tamén redactou unha monografía sobre a obra literaria da novelista, da que se conserva un manuscrito inédito no seu fondo persoal, custodiado na Real Academia Galega.

\footnotetext{
26 Manuel Casás, Páginas de Galicia, Santiago de Compostela, Sucesores de Galicia, 1950, pp. 162. Trátase dunha homenaxe celebrada o 1 de setembro na Reunión Recreativa de Artesáns da Coruña, da que era presidente Casás. A autora escusa a súa asistencia por motivos de saúde e por estar fóra da Coruña. Nesas datas di estar en Mondariz ou Sanxenxo ( $L a$ Voz de Galicia, 20-VIII-1916), aínda que Manuel Casás acabou acusándoa de estar, en realidade, en Meirás.Tampouco acode a novelista galega á inauguración na Coruña do monumento a Concepción Arenal, o día 17 de setembro de 1916, mandando unha carta aberta ao alcalde para desculparse por non estar na homenaxe, nin á homenaxe dedicada a Rosalía de Castro (La Voz de Galicia, 27-VIII-1916, p. 1). 27 Manuel Casás, Páginas de Galicia, Santiago de Compostela, Sucesores de Galí, 1950, pp. 162-163.

${ }^{28}$ No Arquivo da Real Academia Galega, no fondo documental Manuel Casás, hai varias cartas cruzadas entre os dous autores sobre a inclusión deste prólogo.
} 


\section{A INAUGURACIÓN DA ESTATUA}

O acto de homenaxe a Pardo Bazán celebrouse o domingo 15 de outubro de 1916, despois de certas vacilacións na fixación da data. Ese día os xornais coruñeses ofreceron en portada unha ampla cobertura sobre os actos que terían lugar.
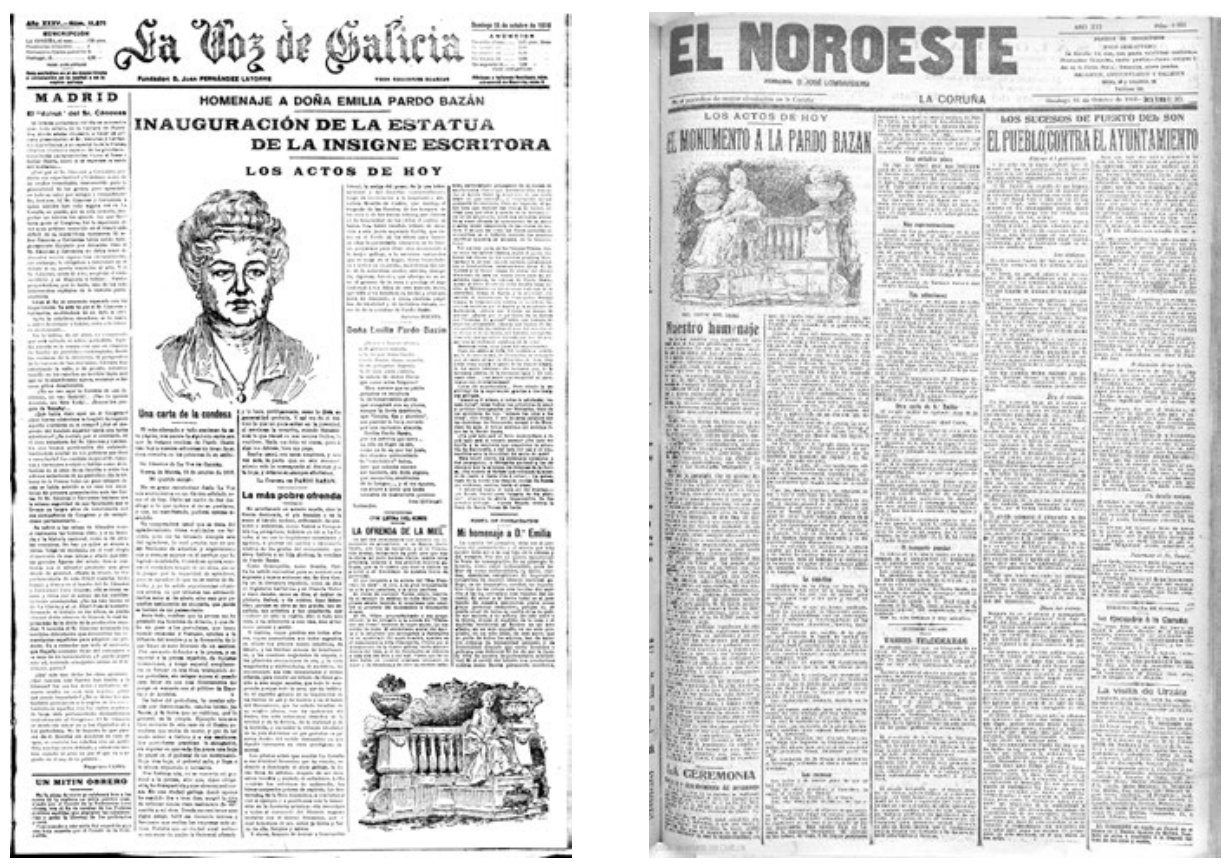

Estes actos comezaron ás once da mañá, reuníndose as autoridades na sala capitular da Casa Consistorial do Concello. Logo diríxense todas elas a María Pita, lugar onde quedou emprazada a comitiva. Ás 11.30 horas deu comezo unha procesión cívica, debidamente organizada, que se dirixiu rumbo aos xardíns, para a cerimonia e inauguración da estatua. En rigorosa orde, primeiro as autoridades, seguidas dos altos funcionarios, centros docentes, institucións académicas e culturais, prensa, corporacións oficiais, colexios especiais, entidades bancarias e mercantís, sociedades de recreo, as representacións foráneas e comisión de Lugo, iniciadora da homenaxe, corporación da Deputación provincial e corporación municipal. Conservamos unha imaxe da procesión, publicada pola revista madrileña Mundo Gráfico, no seu número 261, do 25 de outubro de 1916. Deste acto hai varias imaxes estereoscópicas, que pertencen á colección de fotografías do Arquivo do Reino de Galicia, quizais realizadas por José Villar Martelo. 


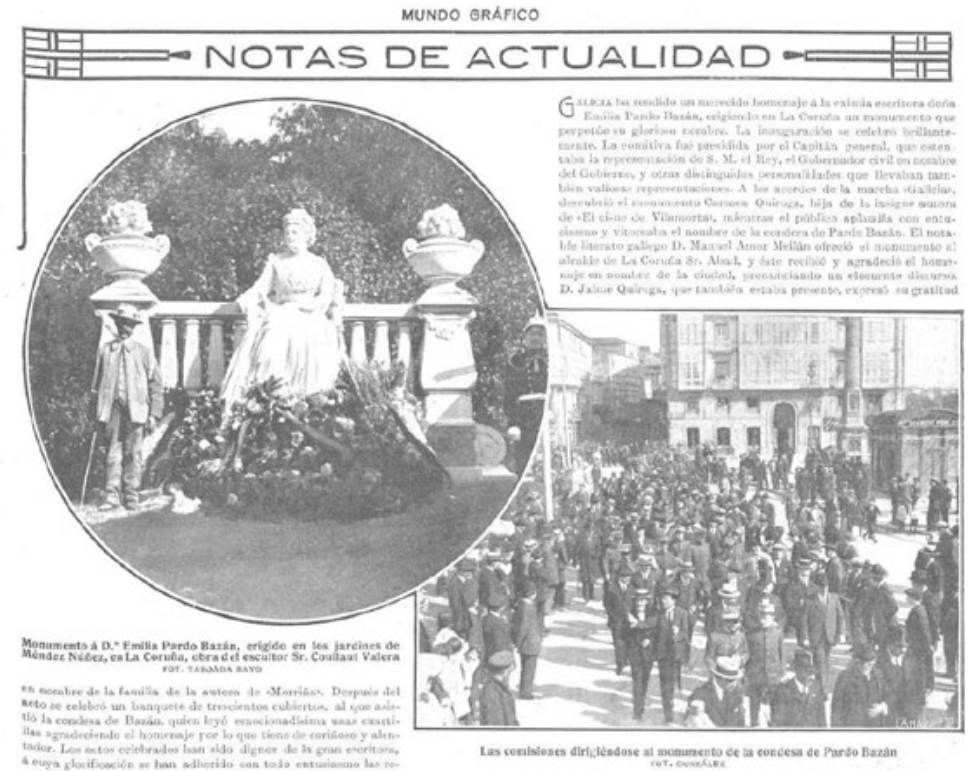

Na velada Carmen, a filla da homenaxeada, acompañada por Abad Conde, o alcalde accidental, descubriu o pano que agochaba a estatua de Pardo Bazán, labrada polo escultor Coullaut Valera. A placa, obra de Julio Wonumburger, era cortesía do Centro Galego de Bos Aires, representado no acto por Julio Dávila.

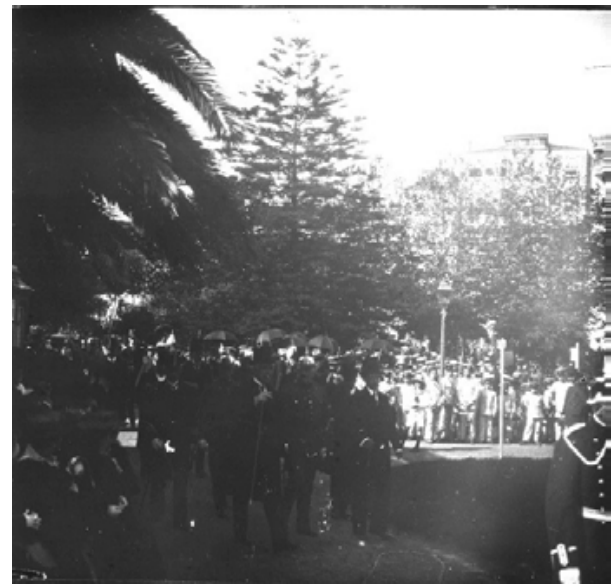

Chegada das autoridades (Arquivo do Reino de Galicia, Colección de fotografías, signatura Fotografía 1081).

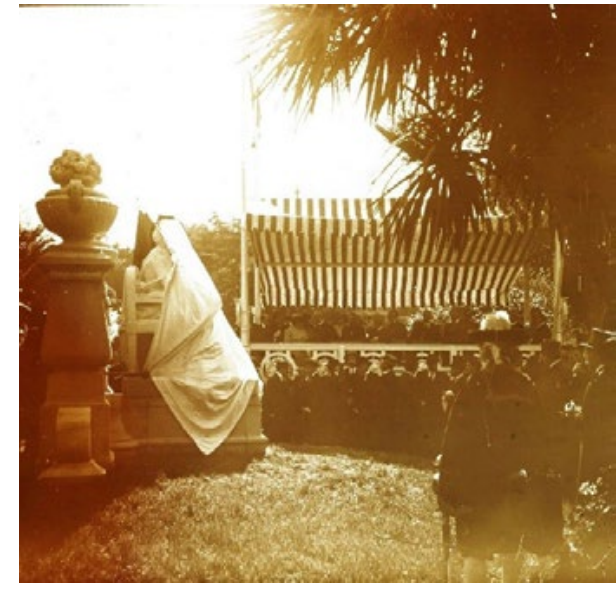

A estátua antes da descuberta (Arquivo do Reino de Galicia, Colección de fotografías, signatura Fotografía 1082). 
No acto, e en primeiro lugar, tomou a palabra Amor Meilán, o ilustrado secretario da comisión lucense, quen explicou nun sentido discurso a xénese do monumento, escusando o retraso dunha homenaxe pensada para tempo atrás, mais outros e debidos laudos pospuxeron o recoñecemento. Tamén lembrou as múltiples adhesións, e ofreceu á cidade da Coruña o tan nobre agasallo. En segundo lugar tomou a palabra Abad Conde, o alcalde accidental, quen rematou a súa locución sinalando os estreitos lazos cordiais que unen A Coruña e Lugo, e agradeceu o labor desenvolvido pola comisión lucense, promotora da homenaxe. En terceiro e último lugar tomou a palabra Jaime Quiroga Pardo Bazán, quen mostrou a súa gratitude ás corporacións adheridas á homenaxe e aos múltiples apoios recibidos, e prometeu non esquecer tan xentil honra recibida.

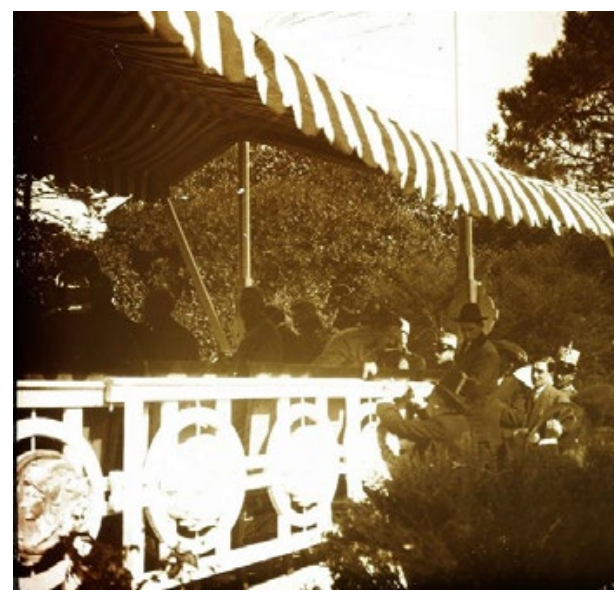

Palco de autoridades (Arquivo do Reino de Galicia, Colección de fotografías, signatura Fotografía 1079).

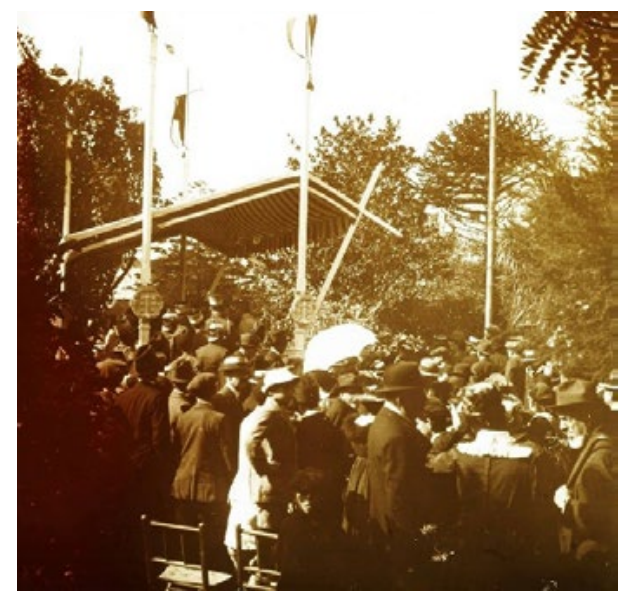

Público (Arquivo do Reino de Galicia, Colección de fotografías, signatura Fotografía 1080).

Ao pé do monumento procederon a colocar as coroas de flores representantes do Ateneo de Madrid, da revista barcelonesa La ilustración artística, do Centro Español de Porto, da colonia coruñesa de Ferrol, do Círculo das Artes de Lugo, representado no acto por Eladio Rodríguez González, e do Centro Galego de Madrid, representado por Blanco Espada.

Como colofón da velada lanzáronse bombas ao aire, e o alumnado das escolas públicas cantou o himno galego.

Logo da inauguración da estatua, á unha e media da tarde, comezou o banquete no pavillón central do mercado da Praza de Lugo, onde sentaron entre douscentos e trescentos comensais. A homenaxeada si asistiu ao xantar, acompañada na mesa presidencial por Amor Meilán -membro da comisión promotora lucense-, Vázquez -representante da delegación de Facenda-, Boente -gobernador civil-, Abad Conde -alcalde accidental-, o marqués de Figueroa e Ozores de Prado, deputados a Cortes pola Coruña, Tapia -presidente da Deputación de Lugo-, Lecea - presidente da Audiencia territorial-, os representantes da Escola Normal, Instituto, Escola de Artes e Obxectos, Escola de Comercio, Delegación 
de Facenda, e Carmen Quiroga Pardo Bazán -filla da homenaxeada. Nas longas mesas dispostas sentaron deputados, banqueiros, militares, concelleiros, avogados, artistas, propietarios, industriais, sacerdotes, xornalistas, catedráticos, comerciantes, funcionarios, médicos, pintores, e outros representantes, aos que acompañou Jaime, o fillo da homenaxeada.

Chegado o momento do brinde, Abad Conde pronunciou un breve discurso, seguido polo do presidente da Deputación de Lugo, quen salientou o labor espontáneo desenvolvido pola comisión iniciadora e promotora de Lugo, e polo da profesora María Barbeito de Martínez Morás, quen gabou a faceta educadora da homenaxeada. Para rematar tomou a palabra dona Emilia. No seu discurso evocou o amor que sentía por Galicia, expresou o estado de confusión sentido ao verse inmortalizada nunha estatua, destacou o incesante traballo e loita feminista desenvolvida ao longo da súa vida, e agradeceu a Lugo e á súa cidade natal a homenaxe recibida.

Mais non rematou aí a homenaxe, xa que os días seguintes sucederon outras xuntanzas e recepcións.

O luns16, o día seguinte da homenaxe, Emilia Pardo Bazán convidou a almorzar en Meirás un círculo íntimo de amizades. Asistiron o señor Tapia, Amor Meilán, Varela Lenzano, López Rúa, Emilio Pan de Soraluce e Casares Quiroga, o capelán de Meirás e o párroco de Coirós. Os convidados regresaron á Coruña xa caída a tarde. Mais non rematou aquí a xornada, xa que a homenaxeada asistiu a unha cea e velada na rúa Tabernas, organizada polo seu veciño Álvaro Torres Taboada, quen quixo sumarse á homenaxe. Asistiu Pardo Bazán, acompañada pola súa filla Carmen, a señora de Torres Sanjurjo e Pedro Barrié de la Maza. Rematada a cea, e xa no café, acudiu a homenaxeala un grupo de amizades, entre as que atopamos María Brandón, Pilar Estrada e os seus respectivos maridos, e os señores Menéndez e Torrado. A velada foi amenizada por unha "rondalla" que rematou a media noite ${ }^{29}$.

O martes 17 de outubro, ás sete da tarde, a condesa acudiu ao Concello, e no salón de plenos da Casa Consistorial foi recibida por unha boa representación da vida local coruñesa, onde atopamos, entre outros, Tella, directora da Escola Normal de Mestras; Barrenechea, presidente da Audiencia; Pascual, o fiscal xefe; Marcelino Vázquez, delegado de facenda; concelleiros e secretario da corporación municipal; Casares Paz; Abad Conde; Joaquín González; Sastre; Meñile; Puga Pequeno; Casares Quiroga, o síndico; e, esta vez si, o alcalde Manuel Casás. No transcurso do acto Pardo Bazán tomou a palabra e leu unhas cuartillas. As súas palabras foron contestadas a continuación por Casás ${ }^{30}$. Neste discurso a condesa fixo un enxalzamento da cidade, agradeceu non só o recoñecemento que a Coruña Ile fixo a ela, senón tamén o que lles facía ás mulleres que dalgunha maneira a enalteceron, e anunciou que na súa cátedra da Universidade de Madrid ocuparía un lugar

\footnotetext{
${ }^{29}$ La Voz de Galicia (17-X-1916).
}

${ }^{30}$ La Voz de Galicia (18-X-1916). 
relevante o ensino da literatura galega. Atopamos o texto do seu discurso reproducido en La Voz de Galicia, o día 18 de outubro ${ }^{31}$.

Nun artigo posterior ao acto de homenaxe, escrito a pedimento da redacción de El Libera $^{32}$ e reproducido en $L a$ Voz de Galicia ${ }^{33}$, Pardo Bazán fixo públicas as súas impresións e expresou as súas emocións sobre todo o acontecido. De seguido reproducimos o artigo citado, no que a condesa insiste na idea de que este acto significa unha ruptura coa tradición: cambiar a celebración de homenaxes post-mortem por homenaxes en vida, e no que expresa a admiración pola escultura, envexa pola muller de pedra que tan ben representa a súa psicoloxía, envexa pola muller de pedra pola que non pasa o tempo, que non avellenta, que manterá o sorriso no transcurso dos séculos, envexa pola muller de pedra que, como a política, non ten entrañas!

\section{$C A B O$}

En 1916, Emilia Pardo Bazán era unha intelectual recoñecida e protagonista habitual en revistas e xornais, tanto pola súa obra como pola súa presenza pública.

Mais será este ano cando a súa valía académica é recoñecida coa concesión da cátedra e a inauguración da estatua na súa cidade natal. Sen dúbida, estes novos laudos e honores axudaron a facer máis visible a súa figura aos ollos dos seus contemporáneos. Porén, a maior proxección pública supúxolle estar máis exposta a críticas mal intencionadas e posibles inimizades persoais, moitas delas filtradas a través de discursos públicos, tal e como mostramos nesta breve revisión sobre a recepción da homenaxe en 1916 ..

Por sorte, no caso da nosa escritora o tempo soubo calmar aquelas liortas de "pequenas miras", deixando no noso recordo os seus méritos e logros. E así, un século despois da inauguración da escultura, podemos afirmar con rotundidade que pola súa figura "non pasa o tempo", e non só por estar a súa imaxe esculpida en pedra, senón por estar esculpida nos materiais máis duradoiros: a admiración e o interese. Lembremos, para rematar, as súas palabras desmentidas polo tempo, xa que finalmente o barro venceu á pedra:

Pero en tanto que vemos en piedra nuestra imagen, nos reconocemos de pobre barro humano, vencidos por los hondos sentires que empañan los cristales de los anteojos y reblandecen el alma más estoica...

\footnotetext{
31 Pódese ler a súa transcrición no Anexo do presente artigo.

32 El Liberal. 8-XI-1916

33 La Voz de Galicia. 10-XI-1916
} 


\section{ANEXOS}

\section{Discurso lido por Emilia Pardo Bazán na recepción no Concello da Coruña, o 17 de outubro de 1916 (La Voz de Galicia, 18-X-1916, p. 2.)}

Permitidme, señores, que vea en vosotros la más genuina y calificada representación de la ciudad donde he nacido, y donde he pasado no poca parte de mi vida, y que llegue a vuestra presencia en esta hora, para mí memorable, a declarar lo que experimento ante la acogida que debe a La Coruña el monumento en que se ha querido perpetuar mi nombre de escritora. Tal homenaje, y más aún la simpatía que puedo creer general y que ha acompañado en manifestación cordialísima, al testimonio de piedra, van más allá de lo que yo hubiese soñado, en esas horas juveniles en que parece abrirse lo infinito a la aspiración devoradora.

Permitidme también aseguraros que, durante el curso de una vida larga, en que he trabajado desde el primer día hasta el último, sin dar lugar al desfallecimiento, me ha guiado, como al pastor una estrella, el anhelo de ofrecer a mi ciudad lo que recogía, Ilámese esta cosecha como queráis, lauros, aprobaciones o notoriedad solamente. Al obtener algo de lo apetecido, como en la reciente ocasión, en que un Gobierno y un ministro embebido de espíritu de adelanto, me ha llevado a la Cátedra, a una de índole especial en que habré de tratar con carácter docente de la literatura gallega; al obtener, digo, lo que halaga y lo que fortifica la voluntad, pensé, involuntariamente, en lo que pensarían mis conciudadanos, y hasta busqué en sus semblantes y en sus conversaciones, con ansiedad tal vez pueril, el reflejo de la impresión recibida, para medir por él la importancia del terreno, palmo a palmo ganado, no sin batalla tenaz y dura.

Este afán de que ciudad madre repitiese mi nombre cuando resonaba fuera, demuestra que era hondo en mí el amor ciudadano, distinto del de la región y del de la patria. El de la ciudad está entretejido con fibras del corazón más íntimas, y se despierta con la menor reminiscencia, a la revuelta de una plaza, al aspecto de pórtico de iglesia, a la sugestión, de algo material, familiar, que es la extensión inmediata de lo doméstico, su natural prolongación. La ciudad es el hogar que se dilata en la calle, en cuanto le rodea y como cosa propia resuena en él.

La ciudad es anterior a la idea de las patrias, o por mejor decir, es la patria primitiva. La patria era entonces la ciudad, y en su almenado recinto terminaba, y en su acrópolis culminaba, y al reconstruir la ciudad arruinada y proscrita, la patria se recobraba y renacía como vemos en la Eneida, donde resucita Troya en otros confines. En épocas más recientes, probaron la sustantividad de la ciudadanía las guerras interciudadanas, como las que Italia con tal ardor sostuvo, alrededor de sus gonfalones las ciudades enemigas, disputándose la superioridad comercial, como hoy siguen combatiendo, aunque en distinto campo y con otras armas, pues la Historia cambia poco. Y nada nos revela nuestra personalidad como el que pretendan atacarla. La ciudad es, en casos tales, un individuo único, animado de los mismos deseos y soliviantado por los mismos intereses.

Y en España, ¿quién no lo sabe, quién lo olvidará? Las ciudades combatieron a su hora y resistieron al régimen más poderoso, a la grandeza cesárea, cuando fue preciso. El nieto 
de Isabel la Católica, casi dueño de Europa, casi poseedor de otro y nuevo continente; aquel que en el mundo no tuvo igual, no subyugó a la ciudad sino desquiciando la organización tradicional de sus dominios y de las instituciones municipales fueron mártires hidalgos y artesanos, unidos en una causa que a todos interesaba, que todos defendían. Y el símbolo de la ciudadanía, el Concejo, institución esencialmente de orden, lo fue de protesta y resistencia, y más tarde, el arte puso de manifiesto esta energía nacional en una obra admirable donde parecía latir el alma española: "El alcalde de Zalamea".

Cuando los descubridores y conquistadores cruzan el Océano, revela su procedencia española que el primer acto de la fundación de la ciudad sea la elección del Concejo. Así como supieron llevar el caballo y el buey y la semilla y la enseñanza, tal cual entonces podía llevarse, trasladaron a los antípodas, no solo como dijo un gran poeta, la lengua de Cervantes y la Cruz del Gólgota, sino la institución recia, libertadora del Concejo. Y cuando las demás naciones de Europa empezaron a hacernos competencia en las tierras nuevas y a minar nuestro poderío, construyeron, no ciudades, porque la ciudad es el Municipio, sino fortines de piratas y factorías de explotadores. Y vemos con emoción sagrada, en la historia de nuestra prodigiosa expansión, a caudillos como Hernán Cortés, que pudieran tener por fueros sus bríos y por pragmáticas su voluntad, devolviendo al Concejo la autoridad suprema, y no ejerciéndolo hasta que el Concejo se la confiere. Así encontramos, al través de las edades, soldada la cadena del derecho.

Hoy, que la ciudad representa para nosotros, si no un concepto de independencia y disgregación respecto a la patria común, un ideal de progreso más accesible por más definido y concreto, y que, sin enseñarnos a lesionar a nadie, nos enseña a velar por nosotros mismos, por nuestros legítimos intereses, yo he sentido con frecuencia que lo realizado por mi pluma en el campo de una extensísima publicidad, no pudiese emularlo mi acción en otro terreno positivo, que me permitiese impulsar a mi pueblo por las vías de un desarrollo fecundo y de iniciativas y empresas que transforman, en estos tiempos de intensa vitalidad, a las colectividades. Sí: he conocido un género de envidia, no vergonzosa hacia los que, desde las esferas del Poder, prestan elementos valiosísimos a las ciudades. He lamentado entonces mi falta, no diré de capacidad, sino de capacitación política, y he deplorado, una vez más, que la mujer, a quien no se ha podido excluir del arte porque no había medio, ni del estudio, porque tampoco cabe, encuentre a la puerta del templo de las leyes a esos dos gigantazos del poema wagneriano, a esos dos fantasmas del ayer que cierran tantas puertas, y que se llaman la preocupación y la rutina. Por eso, sería una utopía, al menos hoy, que yo anhelase dar a mi cara ciudad algo que le permita sostener la competencia con otras urbes y otros litorales, y he venido a ella sin oro en las manos, con sólo alguna rama en que florece la naturaleza, y una lámpara de barro en que se consumió el aceite de algunas veladas estudiosas. Pobre es el don, pero aceptadlo de quien respetuosamente os lo ofrece, y que espera que La Coruña, en quien es religiosa la adoración al valer de las hembras que han enaltecido, poco o mucho, su suelo, esté siempre al lado de la mujer, en cuanto pueda afectar a su legítima aspiración, la única que está por atender todavía. 
Cuando llegue el momento oportuno, vuelva la Coruña la vista hacia esas esculturas y esos monumentos que alguna significación entrañan, y piense que la mujer aguarda todavía su hora, y la aguardará, sabe Dios por qué años. Esto es lo que recuerda a la ciudad madre, en tan solemne momento, su hija más amante, que quisiera descansar mañana en su seno, como en él ha vivido espiritualmente, buscando calor y recostadero de frente acalenturada, en las crisis en que nos sentimos débiles, y en que dudamos de nosotros mismos.

Con tal sentimiento, enteramente venerador, enteramente sumiso y agradecido, saludo a la representación de mi ciudad, y la ofrezco lo poco que todavía de mi puede esperarse, inclinada ante la enseña que ostentáis y la institución de que sois ahora para mi figura visible.

\section{Artigo de Emilia Pardo Bazán para o xornal madrileño El Liberal ${ }^{34}$, reproducido posteriormente en La Voz de Galicia da Coruña, o 10 de novembro de 1916.}

Puesto que lo desea el director de El Liberal, trataré de resumir mis impresiones en una hora señalada de la vida, olvidando que el «yo» «es aborrecible», escandalizando probablementete a los partidarios de la impasibilidad, exponiéndome a interpretaciones subrayadas con malicias, entraré por los repliegues y reconditeces de la conciencia, y analizaré lo que al análisis se resiste, lo que sentí cuando descubrieron mi figura esculpida en piedra. Un pudor, acaso pueril, me ha impedido escribir «mi estatua».

Un exquisito espíritu como Gómez Carrillo, tiene el sutil olfato profesional, y lo que de mí solicita para el periódico no es, por lo menos, dentro de la crónica, cosa trillada. Tal convencimiento es lo primero que descubro al estudiar reflexivamente mis impresiones: que se trata de algo nuevo o insólito. Españoles de leyenda vieron, en otras edades, desfilar su propio entierro: yo he visto alzarse mi propio monumento, con mis ojos mortales, y a fe más me ha admirado que engreído. El engreimiento revela escasa disciplina crítica. La critica es escuela de toda humildad ${ }^{35}$.

El ejemplo de los que saltaron por encima de la rutina de guardar los homenajes para después de la muerte, es posible que sea imitado; idea tan sencilla y lógica sólo necesitaba practicarse, y ante la práctica cesaría la alarma de la grey y quedarían refutadas las objeciones. Hasta esta satisfacción me han brindado: la de creer que por mí se rompe otro molde viejo. Altruistamente, en tal suposición me complacía cuando, desde una terraza de mágica perspectiva, en el vidrio de mis prismáticos, se encuadró la escena: la bandera nacional descorriéndose, y la mujer de piedra, olímpica y blanca, surgiendo sobre el cielo cobalto, con ínfulas de triunfadora.

Y de aquí se originó otra especie de sentimiento elegíaco, piadosa confusión, al recordar a tantos como me precedieron en el camino enriscado y pendiente, y que sólo vueltos ceniza fueron glorificados. ¿Por qué caprichosa indulgencia de la suerte se me

\footnotetext{
34 Artigo publicado o 8 de novembro de 1916.

35 Estes dous primeiros parágrafos omítense no xornal coruñés por falta de espazo, como se afirma nunha breve introdución na que se advirte a procedencia do texto.
} 
otorgó a mí lo que a ellos no? Nadie supondrá que lo atribuyo a diferencias de calidad, ni siquiera de cantidad. Es que, acaso, hemos Ilegado a afinar también, como se han afinado otras cosas, el sentimiento de la bondad, el anhelo de hacer menos tristes a las almas, y a impulsos de la bondad latieron, seguramente, algunos corazones cuyo temple conozco bien, y que concibieron el plan al unísono, en una vieja ciudad gallega, durante una noche invernal brumosa y fría, a la hora en que, concluida la jornada, desechadas sus preocupaciones múltiples y fatigosas, por la chimenea entran los ideales brujos cabalgando en escobas de lumbre, y sugieren los proyectos atrevidos y las originalidades del sentir. Y yo pensaba en estos hombres agrupados para fantasear lo que nunca se había hecho, y también, porque es justo no olvidar a nadie en aquellos otros (algunos ya duermen el sueño último) que hace largos años, en un paseo por "Auriabella", exclamaron con férvida ilusión: "Aquí será donde el monumento se alce".

A la vez -no son seriales, sino simultáneas, estas impresiones-que me confundía en la persuasión de recibir más, mucho más de lo merecido, la levadura humana bullía en mí, y daba en creer que si no justicia seca, era tanto bien compensación y consuelo. Acudían a mi memoria las heridas, los magullamientos, las espinas de mi carrera artística, y lo caro que se me cobró, frecuentemente, el haber escuchado a mi vocación y seguido su Ilamamiento. Acudían las injustas exclusiones, las cerradas puertas que ha tiempo debieron franquearse, los que me lanzaron piedras buscando que diesen donde más dolía, los que por la tela de mis faldas juzgaron mi obra, y fueron, en parte, los artífices que, en unión con el escultor famoso, labraron esa mujer de piedra, dorada por la luz radiante de un espléndido día de octubre. Lo arbitrario y lo violento provoca inevitables reacciones de equidad, caballerescas como de raza, y lo atestiguan en mis gavetas innumerables artículos, donde late y se desborda este espíritu español, transmitido a la América que descubrimos, y a la cual transfundimos nuestra sangre hidalga. Haciendo mesura, barriendo el suelo con la pluma del chambergo, contestaron a las bellaquerías, a las prosas enarboladas como saeta de salvaje. Y toda la generosidad que he encontrado y que me ha envuelto en su onda de calor, la concreta y perpetúa la mujer de piedra, a cuyos pies se hacinan las coronas.

Al continuar el análisis, confesaré un sentimiento envidioso... cuando parecería que nada debiese envidiar. Envidio, lo declaro, a la mujer de piedra.

Envidiaba su reposo, su sencillez, aquella sonrisa que juega en sus labios, tan reveladora. Al marcar esta sonrisa y al colocar la figura, blandamente sentada, sin afectación y sin énfasis, en familiar actitud, el artista, que ya otras veces había modelado mis facciones, se inspiró en el conocimiento de mi psicología, en mi ánimo igual y sereno, en la sesga corriente de mi carácter. Por dentro, sólo pueden mantenerse invariablemente en tal postura las mujeres de piedra... Las de carne y hueso, nadie lo dudará, mal se jactarían de esa impasibilidad feliz. Ahí está la razón de mi envidia. ¿Quién tasa la ventura que representa el sostener en las manos una pluma que jamás ha de escribir un renglón, un libro que nadie leerá, y conservar el misterioso sosiego de las divinidades egipcias e indostánicas, que también sonríen de un modo imperceptible y como en éxtasis y, detestando "el movimiento que desplaza las líneas", jamás ríen y jamás Iloran? 
Dichosa mujer de piedra, a la cual el tiempo no injuria, resbalando impotentes los años por su lisa frente, sin imprimir en ella una arruga, sin doblar su erguida espalda, sin apagar sus ojos, faltos de pupila y abiertos ampliamente a la claridad de soles y lunas, al parpadeante esplendor de las estrelladas noches. ¡Dichosa mujer, siempre bañada en aire libre, siempre impregnada de brisa salitrosa del Cantábrico, en el puerto marinedino!

¿No he de envidiarla? Olímpica mujer a quien el paso de las horas es insensible, y que nunca verá marchitarse su intensa juventud, el fuerte estío en que está representada. Transcurrirán lustros, siglos, y sonreirá lo mismo que ahora, mientras a su alrededor corretearán niños de testas rubias que han de llegar a ser hombres y venir, cuando caducos, a holgar en los bancos del paseo, donde cuchichearán parejas de novios, sucediendo a otras que cuchichearon, sin que se interrumpa el eterno dúo, aunque lo entonen voces nuevas. En torno de la mujer de piedra, el poeta, si recuerda lo que otros poetas cantaron, podrá convertir en melancolía la misma terca juventud de la estatua, ante la fugaz procesión de la vida, en constante disolución, transitoria, arrastrada por el "devenir", que no es sino el acabar, el borrarse y pulverizarse cuanto parecía destinado a durar siempre. ¡Y la mujer de piedra allí permanecerá, sin mover los dedos que sostienen la pluma, que asaz los movió su modelo!

Y aún falta lo más envidiable de todo... la blanca mujer, de tronco macizo, es como la política. ¡No tiene entrañas!

Yo las tengo... y por eso mi emoción se transmite a lo más íntimo de mi organismo, madurándome, como el sol a la fruta otoñal, para desprenderme del árbol cuando plazca a Dios... Porque (pensémoslo gravemente) estas esencias de nardo con que nos ungen, nos embalsaman para el reposo sin fin, son la máscara de oro de la momia, que oculta el estrago de las destrucciones. Y el análisis conduce a tal resultado: que todo es según debe ser, pues las piedras materializan y perpetúan lo único que de nosotros importa y vale y dan cuerpo incorruptible a nuestro ensueño artístico y poético, que aun sin llegar en grandes y belleza adonde quisiéramos, nos ha ennoblecido. Por él nos fijan en piedra, y por él no lo fuimos nunca; por él no nos dejamos petrificar, y aleteó vivaz nuestra fantasía, y movible e inquieta se convirtió a los horizontes nuevos y se refrescó, y se remozó, y fue mariposa, hija de las libres primaveras...

Pero en tanto que vemos en piedra nuestra imagen, nos reconocemos de pobre barro humano, vencidos por los hondos sentires, que empañan los cristales de los anteojos y reblandecen el alma más estoica...

La Condesa de Pardo Bazán 